\title{
Hasta Eğitimi İçin Geliştirilen Hipertansiyon, Hasta Takip Kartı ve Sağlıklı Yaşam Broşürlerinin Değerlendirilmesi
}

\author{
Evaluation of Hypertension, Patient Tracking Card and Healthy Life Brochures \\ Developed for Patient Education
}

\author{
Merve Tokatı Doğan' (D) Müberra Erkaya Tosun' (I) Banu Ekinci ${ }^{2}$ (D) \\ Zübeyde Özkan Altunay ${ }^{3}$ (D) Nevin Çobanoğlư (D) Fatma Tamkoç Gürbüztürk $^{5}$ \\ Şükriye Seçil Sis ${ }^{6}$ (D) Seçil Özkan ${ }^{7}$ (1)
}

\footnotetext{
${ }^{1}$ Arş. Gör. Dr., Gazi Üniversitesi Tıp Fakültesi, Halk Sağlığı Ana Bilim Dalı, Ankara, Türkiye, mervetokatlidogan@gazi.edu.tr

${ }^{1}$ Arş. Gör. Dr., Gazi Üniversitesi Tıp Fakültesi, Halk Sağlığı Ana Bilim Dalı, Ankara, Türkiye, muberraerkaya@gazi.edu.tr

2 Uzm. Dr., Sağlık Bakanlığı, Halk Sağlığı Genel Müdürlüğü, Ankara, Türkiye

${ }^{3}$ Dr., Sağlık Bakanlığı, Halk Sağlığı Genel Müdürlüğü, Ankara, Türkiye

${ }^{4}$ Tıb. Tek., Sağlık Bakanlığı, Halk Sağlığı Genel Müdürlüğü, Ankara, Türkiye

${ }^{5}$ Hem., Sağlık Bakanlığı, Halk Sağlığı Genel Müdürlüğü, Ankara, Türkiye

${ }^{6}$ Danışman, Sağlık Bakanlığı, Halk Sağlığı Genel Müdürlüğü, Ankara, Türkiye

${ }^{7}$ Prof. Dr. Gazi Üniversitesi Tıp Fakültesi, Halk Sağlığı Ana Bilim Dalı, Ankara, Türkiye
}

Öz

Amaç: Bu çalışmada geliştirilmiş olan Hipertansiyon, Hasta Takip Kartı ve Sağlıklı Yaşam broşürlerinin değerlendirilmesi amaçlanmıştır. Yöntem: Hasta eğitiminde kullanılmak üzere geliştirilen broşürler dahiliye polikliniklerine muayeneye gelen 64 hastaya gösterilip okutularak yüz yüze görüşme tekniği ile anket uygulanmıştır. Tanımlayıcı tipteki bu çalışmanın sonuçları yüzdelerle sunulmuştur. Ayrıca her broşür için broşürü geliştirmeyen uzmanlardan yazılı öneriler alınmıştır.

Bulgular: Katıımcıların tamamı cümlelerin kendilerine hitap ettiğini belirtirken, \%80'den fazlası ise anlamadığı terim olmadığını ifade etmiştir. Ana konu katılımcıların neredeyse tamamı tarafından anlaşılmıştır. Katıımcıların tamamı yazı tipi ve yazı büyüklüğünü uygun bulmuştur. Madde madde listelerin okumalarını kolaylaştırdığı yine tamamı tarafından ifade edilmiştir. Karışık tablo ve grafik olmadığını ifade etmişlerdir. Fakat katıımcıların yarısından fazlası yapması gerekenlerin neden önemli olduğunun yeterince anlatımadığını düşünmüştür. Tansiyon ölçümü, randevu için nereye gidileceği, ilaçlarını nasıl alacakları konularında verilen bilgileri yetersiz bulmuşlardır.

Sonuç: Sonuç olarak sağlık eğitim materyallerinin birey/hasta eğitimindeki önemine ve sağlık okuryazarlığı düzeylerinin geliştirilmesine olan katkısına dikkat çekilmiştir. Etkili sağlık eğitim materyali hazırlarken dikkat edilecek hususlara yer verilmiştir.

Anahtar Kelimeler: Halk Sağlığı, Sağlık Okuryazarığı, Materyal Geliştirme, Görsel Araçlar, Sağlık Eğitimi Materyalleri. 


\begin{abstract}
Objective: The aim of this study is to evaluate the Hypertension, Patient Tracking Card and Healthy Life brochures developed for patient education

Methods: Face-to-face interview and questionnaire techniques were conducted to 64 patients who came to the outpatient clinics for examination, by introducing brochures developed for patient education them to read. The results of this descriptive study are presented in percentages. In addition, written recommendations were received for each brochure from experts who did not participate in developing the brochures.

Results: Where all of the participants stated that the sentences were appealed to them, more than $80 \%$ of the participants expressed that there was no term they were not able to understand. The main topic was understood by almost all participants. All of the participants found the font and size of the text appropriate. All of the participants stated that item-by-item lists make it easier for them to read. They stated that there were no complicated charts and graphs. However, more than half of the participants thought that why "what to do"s are important was not explained adequately. They found the information given for blood pressure measurement, where to go for an appointment, and how to take their medications insufficient.
\end{abstract}

Conclusion: As a result, attention was drawn to the importance of health education materials in patient education and its contribution to the development of health literacy levels. The points to be considered while preparing effective health education material are included.

Keywords: Public Health, Health Literacy, Developing Materials, Visual Materials, Health Education Materials.

\section{GiRiş}

Önlenebilir ve tedavi edilebilir bir hastalık olan hipertansiyon; ülkemizde ve dünyada en sık görülen kronik hastalık olmasıyla birlikte küresel bir halk sağlığı sorunudur. Kardiyovasküler ve renal olaylara, yeti yitimine ve erken ölüme sebep olmaktadır (Aydoğdu et al., 2019). Kan basıncı; sistemik dolaşımda arteriyel damarlarda dolaşan kanın damar çeperine uyguladığı basınçtır. Erişkinlerde tekrarlanan klinik ölçümler ile sistolik kan basıncının $\geq 140 \mathrm{mmHg}$ ve/veya diyastolik kan basıncının $\geq 90 \mathrm{mmHg}$ olması hipertansiyon olarak tanımlanır (Aşkın, Tanrıverdi, Türkmen, \& Aktürk, 2018). Kan basıncını düşürmenin morbidite ve mortaliteyi ciddi ölçüde azaltabildiğini gösteren birçok kanıt vardır. Dengeli beslenme, düzenli aktivite, sağlıkı tuz kullanımı gibi yaşam tarzı değişikleri ve ilaç tedavi stratejileri, kan basıncındaki bu azalmayı başarabilir. Buna rağmen, kan basıncı kontrol oranları dünya çapında zayıf kalmaktadır ve tatmin edici olmaktan uzaktır (Çakır, 2017).

Hipertansiyon kontrolünün sağlanmasında, başarıı bir hekim-hasta iş birliği gerekir. Kan basıncı ölçümü, tedavinin düzenli bir şekilde sürdürülebilirliği, sağlıklı yaşam tarzı değişiklikleri konularında hastaların yeterli bilgi ve birikime sahip olması önemlidir. Bu sebeple hedef kitle tanınmalı, bilgi intiyaçları bilinmeli, uygulamalarını istediğimiz bilgiyi kavrama yetenekleri öğrenilmelidir. Hasta eğitimi bu bilgiler ışığında verildiğinde faydalı olabilir (Çalışkan, 2019). Bu süreçte evrensel sağlık okuryazarlığı ilkelerini benimsemek, sade bir dil ile iletişim kurmak, bir veya iki temel mesaja odaklanmak, yavaş konuşmak, öğretme tekniğini kullanmak ve anlaşılır yazılı materyaller kullanmak, herkes tarafından anlaşılmasına ve sonuçların iyileştirilmesine yardımcı olacaktır.
Bireyin sağlık okuryazarlı̆ı̆ düzeyi ise sağlığın geliştirilmesinde önemli belirleyicilerden biridir. Sağlık okuryazarlı̆ı; hastaların tıbbi bakımları ve kişisel sağlıkları hakkında iyi kararlar vermek için sağlıkla ilgili bilgileri bulma, anlama ve kullanma yeteneğidir (Weiss, 2014). Türkiye'de sağlık okuryazarlığı \%68,9 yetersiz/sınırlı düzeydedir ve bu durum sağlığın geliştirilmesinde, sağlıkta iyilik halinin sürdürülmesinde önümüzdeki en büyük engellerden biridir (Avcı \& Özkan, 2019). Sağlık okuryazarlığı düzeyi yetersiz bireyler; sağlıkla ilgili bilgi ve mesajların anlaşılmasında zorluklar yaşar. Bu bireylerin hastalanma riski yüksek, tedavi yöntemlerini anlama düzeyi düşük, hastanede yatış oranı fazladır (Kindig, Panzer, \& Nielsen-Bohlman, 2004).

Sağlık okuryazarlığı; okunan veya dinlenen bilgiyi değerlendirdikten sonra karar verme, karara katılma ve hayata uyarlamadır. Sağlık alanında bireylerin en sık karşılaştığı materyaller; ilaç reçeteleri, broşürler, afişler, hekimlerin tedavi ve teşhise yönelik direktifleri, aydınlatılmış onam formlarıdır. Sağlık çalışanlarının en sık kullandığı eğitim materyalleri ise sunumlar, videolar, kitaplar, broşürler, afişler, resimli rehberler ve modellerdir (Çalışkan, 2019). Hastalara verilen her türlü yazılı materyallerin tıpkı sözlü talimatlarımız gibi anlaşılması kolay olmalıdır. Sağlık okuryazarlığı göz önünde bulundurularak hasta bilgi materyallerinin nasıl oluşturulacağını açıklayan çok sayıda kılavuz bulunmaktadır. Ancak mevcut materyallerin çok azı bu kriterleri gerçekten karşılamaktadır.

Hasta eğitimi araçları, anlaşılmasını kolaylaştıran özelliklere dikkat edilerek oluşturulmalıdır. Hastalığın patofizyolojisi hakkında değil, hastaların yapması gerekenler hakkında bilgi verilmelidir. Tıbbi kelimelerden ve ikiden fazla heceli sözcüklerden kaçınılmalıdır. İçeriği düz metin yerine madde işaretli listeler veya soru-cevap biçiminde 
sunulmall, çok sayıda beyaz boşluk eklenmelidir. İçeriği ifade eden resimler kullanımalıdır. Sadece hastanın bilmesi veya yapması gerekenler için gerekli olan bilgiler dahil edilmelidir (Weiss, 2014). Bu şekilde geliştirmiş olduğumuz görsel materyaller, hastalar tarafından daha kolay anlaşılır olacaktır ve hasta eğitimine büyük bir katkı sağlayacaktır. Bu nedenle broşürler hazırlandıktan sonra uygunluğu ve kullanılabilirliği değerlendirilmelidir (Çalışkan, 2019).

Ülkemizde de sağlık eğitiminde görsel materyallerin geliştirilip kullanılması sürecini incelediğimizde ise 1926'da küçük ölçüde başlatılan sağlık broşürleri ve renkli duvar afişleri basımının 1936'da artııılığı, 1963 sonrasında ise bu materyallerin nitelik ve nicelik açısından geliştiğini görmekteyiz. Bu süreçte 1969 yılına kadar sağlık eğitimi etkinliklerini geliştirebilmek için her il sağlık müdürlüğünün bünyesinde "sağlık eğitimi ünitesi" kurulmuştur. Sağlık eğitimlerinde kullanılmak üzere "kitap, broşür, afiş, slayt, film" gibi eğitim malzemeleri hazırlanmıştır (Tüzün \& Özkan, 2019). Görsel materyallerin geçmişte olduğu gibi gelecekte de sağlık çalışanlarının kullandığı yardımcı araçların başında geleceği açıkça ortadadır. Materyalleri oluştururken uygunluk ve etkinlik göz önünde bulundurulmall, toplumun sağlık okuryazarlığı düzeyleri dikkate alınmalı, hazırlanan materyaller ön değerlendirmeden geçirilerek en anlaşılır haliyle sunuma hazır hale getirilmelidir.

$\mathrm{Bu}$ çalışmada geliştirmiş olduğumuz Hipertansiyon, Hasta Takip Kartı ve Sağlıkı Yaşam broşürlerinin değerlendirilmesi amaçlanmıştır.

\section{GEREÇ VE YÖNTEM}

Bu çalışma 'Türkiye'de Kan Basıncı Kontrolünün İyileştirilme Projesi" içeriğinde yapılmıştır. Hasta eğitiminde kullanılmak üzere dahiliye uzmanı, halk sağlıçı ve iletişimcilerden oluşan bir uzman grubu ile broşürler geliştirilmiştir.(Ek1,Ek2,Ek3) Geliştirilen broşürler bireylere sunulmadan önce anlaşılması, kavranması konusunda ön değerlendirmeye alınmıştır. Değerlendirme formu da literatür taranarak uzman grup tarafından geliştirilmiştir. Polikliniklere muayeneye gelen 64 hastaya gösterilip okutularak yüz yüze değerlendirilmiştir. Değerlendirme kontrol listelerindeki her bir ifadeye katılımları evet, hayır şeklinde alınmıştır. Ayrıca her broşür için broşürü geliştirmeyen uzmanlardan yazılı öneriler alınmıştır. Kontrol listesindeki her bir ifadenin yüzdeleri sunulmuştur. Bu çalışma 11.12.2018 tarih ve Araştırma Kod No: 2018434 onay kodu ile Gazi Üniversitesi etik komisyonundan onay almıştır.

\section{BULGULAR}

$\mathrm{Bu}$ çalışmada 64 birey/hastaya Hipertansiyon, Hipertansiyon Takip Kartı ve Sağlıkı Yaşam broşürleri gösterilip okutularak yüz yüze görüşleri alınmıştır. Tablo 1, Tablo 3 ve Tablo 5 'te broşürlerin birey/hasta anlama durumlarının yüzdeleri sunulmuştur.

Hipertansiyon broşüründe yüksek tansiyonun tanımına ve sınır tansiyon değerlerine yer verilmiştir. Tansiyonu kontrol altına almak amacıyla yapılması gerekenler ifade edilmiştir. Tansiyonu ölçmeden önce ve ölçüm sırasında yapılması gerekenlere dikkat çekilmiştir. Tansiyonun düzenli izleminin ve kayıt altına alınmasının önemi vurgulanmıştır. Bir seferde en az 2 ölçüm yapılması ve ortalamasının kaydedilmesi ifade edilmiştir. Hipertansif ilaç kullanımında dikkat edilecek hususlara yer verilmiştir.

Tablo 1. "Hipertansiyon" Broşürü Birey/Hasta İçin Anlama Durumları Yüzdeleri

\begin{tabular}{|l|c|c|}
\hline & Evet & Hayır \\
\hline 1.Ana konusu anlaşılıyor. & 100,00 & - \\
\hline $\begin{array}{l}\text { 2.Yüksek tansiyonun ne olduğu } \\
\text { açıklanmış. }\end{array}$ & 93,8 & 6,3 \\
\hline $\begin{array}{l}\text { 3.Yüksek tansiyonla ilgili ne yapmam } \\
\text { gerektiği yazılmış. }\end{array}$ & 81,3 & 18,8 \\
\hline $\begin{array}{l}\text { 4.Nasıl tansiyon ölçüleceğini } \\
\text { anlayabildim. }\end{array}$ & 68,8 & 31,3 \\
\hline $\begin{array}{l}\text { 5.Yapmam gerekenlerin neden önemli } \\
\text { olduğu yazılmış. }\end{array}$ & 56,3 & 43,8 \\
\hline $\begin{array}{l}\text { 6.Testler, ilaçlar ve randevular için } \\
\text { nereye gideceğim var. }\end{array}$ & 6,3 & 93,8 \\
\hline 7.ilacımı nasıl alacağım var. & 75,0 & 25,0 \\
\hline 8.Anlamadığım terim yok. & 100,0 & - \\
\hline 9.Yazı büyüklüğü okumam için uygun. & 100,0 & - \\
\hline 10.Yazı tipi okumam için uygun. & 100,0 & - \\
\hline $\begin{array}{l}\text { 11.Uzun, okuması zor gelen paragraf } \\
\text { yok. }\end{array}$ & 100,0 & - \\
\hline 12.Cümleler bana hitap ediyor. & 100,0 & - \\
\hline 13.Karışık tablo veya grafik yok. & 100,0 & - \\
\hline 14.Sayfalar çok yoğun. & 100,0 & - \\
\hline $\begin{array}{l}\text { 15.Konu içindeki bölümleri } \\
\text { ayırabiliyorum. }\end{array}$ & 93,8 & 6,8 \\
\hline $\begin{array}{l}\text { 16.Madde madde listeler okumamı } \\
\text { kolaylaştırıryor. }\end{array}$ & 100,0 & - \\
\hline 17.Kültürel yapıma uygun resimler var. & 87,5 & 12,5 \\
\hline 18.Bilgiler kültürel olarak bize uygun. & 56,3 & 43,8 \\
\hline
\end{tabular}


"Hipertansiyon" broșürü birey/hasta için anlama durumları yüzdelerini gördüğümüz Tablo1'de katılımcıların tamamı anlamadığı terim olmadığını, yazı tipi ve büyüklüğünün okuması için uygun olduğunu, uzun ve okuması zor gelen paragraf olmadığını, cümlelerin kendilerine hitap ettiğini, karışık tablo veya grafik olmadığını, madde madde listelerin okumayı kolaylaştırdığını ifade etmiştir. İlacını nasıl alacağının anlaşıldığını katılımcıların \%75'i, tansiyonun nasıl ölçüleceğinin anlaşıldığını \%68,8'i belirtirken, yapması gerekenlerin neden önemli olduğunu anlaşıldığını ve bilgilerin kültürel olarak kendilerine uygun olduğunu \%56,3'ü ifade etmiştir. Sadece \%6.3'ü ise testler, ilaçlar ve randevular için nereye gideceği bilgisinin olduğunu işaret etmiştir. Ayrıca katılımcıların tamamı sayfaların çok yoğun olduğunu belirtmiştir. Tablo2'de bulunan hipertansiyon broşürü için uzman önerilerinin hastalar tarafından da ifade edildiği görülmektedir. Altmış dört hastamızın en çok verdiği altı öneri tabloda yer almaktadır.

\section{Tablo 2. “Hipertansiyon Broşürü” İçin Uzman Önerileri}

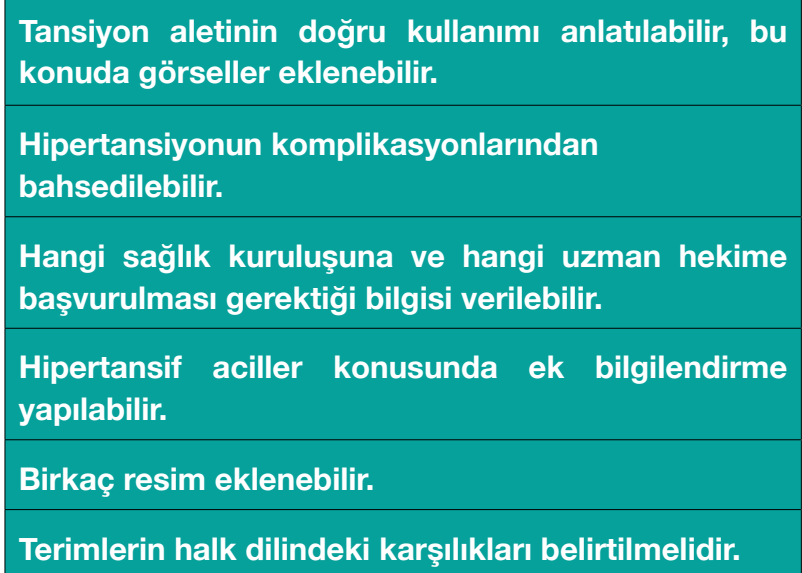

"Hipertansiyon Takip Kartı" broşüründe yüksek tansiyonun sınır değerlerine yer verilmiştir. Tansiyon ölçümünden önce ve ölçüm sırasında dikkat edilmesi gereken durumlar vurgulanmıştır. Tarih, saat, büyük tansiyon, küçük tansiyon, nabız ve ilaç bölümlerinin bulunduğu hasta takip kartına yer verilmiştir. İlaçların dozunun ve kullanım süresinin hekimler tarafından belirlenmesi ve bu süreçte hekim önerilerinin dışına çıkılmaması gerektiği ifade edilmiştir.
Tablo 3. "Hipertansiyon Takip Kartı" Broşürü Birey/ Hasta İçin Anlama Durumları Yüzdeleri

\begin{tabular}{|c|c|c|}
\hline & Evet & Hayır \\
\hline 1.Ana konusu anlaşılıyor. & 93,8 & 6,3 \\
\hline $\begin{array}{l}\text { 2.Yüksek tansiyonun ne olduğu } \\
\text { açıklanmış. }\end{array}$ & 62,5 & 37,5 \\
\hline $\begin{array}{l}\text { 3.Yüksek tansiyonla ilgili ne yapmam } \\
\text { gerektiği yazılmış. }\end{array}$ & 68,8 & 31,3 \\
\hline $\begin{array}{l}\text { 4.Nasıl tansiyon ölçüleceğini } \\
\text { anlayabildim. }\end{array}$ & 75,0 & 25,0 \\
\hline $\begin{array}{l}\text { 5.Ölçülen tansiyonun verilen tabloda } \\
\text { nasıl gösterildiğini anladım. }\end{array}$ & 81,3 & 18,8 \\
\hline $\begin{array}{l}\text { 6.Yapmam gerekenlerin neden önemli } \\
\text { olduğu yazılmış. }\end{array}$ & 31,3 & 68,8 \\
\hline $\begin{array}{l}\text { 7.Testler, ilaçlar ve randevular için } \\
\text { nereye gideceğim var. }\end{array}$ & 25,0 & 75,0 \\
\hline 8.ìlacımı nasıl alacağım var. & 75,0 & 25,0 \\
\hline 9.Anlamadığım terim yok. & 81,3 & 18,8 \\
\hline 10.Yazı büyüklüğü okumam için uygun & 100,0 & - \\
\hline 11.Yazı tipi okumam için uygun. & 100,0 & - \\
\hline $\begin{array}{l}\text { 12.Uzun, okuması zor gelen paragraf } \\
\text { yok. }\end{array}$ & 100,0 & - \\
\hline 13.Cümleler bana hitap ediyor. & 100,0 & - \\
\hline 14.Sayfalar çok yoğun. & 6,3 & 93,8 \\
\hline $\begin{array}{l}\text { 15.Konu içindeki bölümleri } \\
\text { ayırabiliyorum. }\end{array}$ & 100,0 & - \\
\hline $\begin{array}{l}\text { 16. Madde madde listeler okumamı } \\
\text { kolaylaştırıyor. }\end{array}$ & 100,0 & - \\
\hline 17.Kültürel yapıma uygun resimler var. & 93,8 & 6,3 \\
\hline 18.Bilgiler kültürel olarak bize uygun. & 93,8 & 6,3 \\
\hline
\end{tabular}

"Hipertansiyon Takip Kartı" broşürü birey/hasta için anlama durumları yüzdelerini Tablo 3'te incelediğimizde katılımcıların \%75'i nasıl tansiyon ölçüleceğini anladığını ve ilacını nasıl alacağının yer aldığını, \%68,8'i hipertansiyon ile ilgili ne yapılması gerektiğinin açıklandığını, \%62,5'i hipertansiyonun ne olduğunun açıklandığını ifade etmiştir. Yapması gerekenlerin neden önemli olduğunun yazıldığını belirtenler \%31,3, testler, ilaçlar ve randevular için nereye gideceğinin olduğunu belirtenler ise \%25'tir. Katılımcıların sadece \%6.3'ü ise sayfaların çok yoğun olduğunu belirtmiştir.

Hipertansiyon Takip Kartı broşürü için uzman önerileri alınmıştır. Hasta önerileri de uzman önerileri ile benzerlik göstermektedir. En çok verilen yedi öneri ise Tablo 4'te yer almaktadır. 
Tablo 4. "Hipertansiyon Takip Kartı" Broşürü İçin Uzman Önerileri

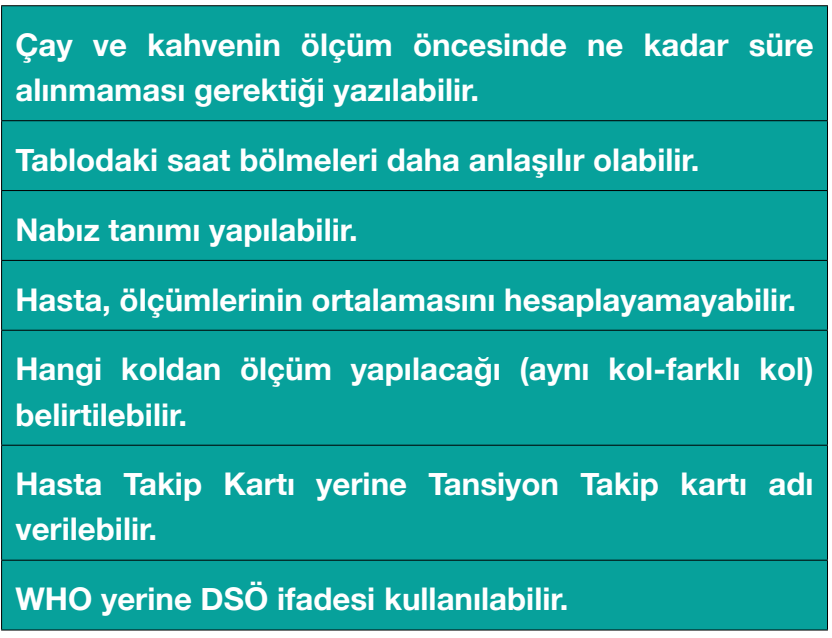

"Sağlıklı Yaşam" broşüründe yaşam tarzının sağlıkl davranışlarla değiştirilmesine yönelik önerilere yer verilmiştir. Stresten uzak durulması gerektiği ve fiziksel aktivitenin önemi vurgulanmıştır. Tüketilmesi ve kaçınılması gereken besin maddelerine ayrı başlıklar altında dikkat çekilmiştir. Yüksek tansiyonlu hastaların uygulaması gereken düzenli fiziksel aktivite programı belirtilmiştir. Sigara ve alkolden uzak durulmasının önemi açıklanmıştır.

\section{Tablo 5. "Sağlıklı Yaşam" Broşürü Birey/Hasta İçin Anlama Durumları Yüzdeleri}

\begin{tabular}{|c|c|c|}
\hline & Evet & Hayır \\
\hline 1.Ana konusu anlaşılıyor. & 100,0 & - \\
\hline 2.Sağlıklı yaşamın ne olduğu açıklanmış. & 93,8 & 6,3 \\
\hline $\begin{array}{l}\text { 3.Sağlıklı yaşamak için ne yapmam } \\
\text { gerektiği yazılmış. }\end{array}$ & 81,3 & 18,8 \\
\hline $\begin{array}{l}\text { 4.Yapmam gerekenlerin neden önemli } \\
\text { olduğu yazılmış. }\end{array}$ & 62,5 & 37,5 \\
\hline 5.Danışmanlık için nereye gideceğim var. & 87,5 & 12,5 \\
\hline 6.Anlamadığım terim yok. & 93,8 & 6,3 \\
\hline 7.Yazı büyüklüğü okumam için uygun. & 100,0 & - \\
\hline 8. Yazı tipi okumam için uygun. & 100,0 & - \\
\hline 9.Uzun, okuması zor gelen paragraf yok. & 87,5 & 12,5 \\
\hline 10.Cümleler bana hitap ediyor. & 100,0 & - \\
\hline 11.Karışık tablo veya grafik yok. & 93,8 & 6,3 \\
\hline 12.Sayfalar çok yoğun. & 31,3 & 68,8 \\
\hline 13.Konu içindeki bölümleri ayırabiliyorum. & 87,5 & 12,5 \\
\hline $\begin{array}{l}\text { 14.Madde madde listeler okumamı } \\
\text { kolaylaştırıyor. }\end{array}$ & 93,8 & 6,3 \\
\hline 15.Kültürel yapıma uygun resimler var. & 87,5 & 12,5 \\
\hline 16.Bilgiler kültürel olarak bize uygun. & 100,0 & - \\
\hline
\end{tabular}

"Sağlıklı Yaşam" broşürü birey/hasta için anlama durumları yüzdelerini Tablo 5'te görmekteyiz. Katılımcıların \%80'inden fazlası sağlıklı yaşam broşürünün ana konusunun anlaşıldığını, sağlıklı yaşamın ne olduğunun ve neler yapılması gerektiğinin açıklandığını, yazı tipinin ve büyüklüğünün uygun olduğunu, broşürün anlaşılır ve okunması kolay olduğunu, bilgilerin ve resimlerin kültürlerine uygun olduğunu, danışmanlık için nereye gidecekleri bilgisine ulaşabildiklerini ifade etmiştir. Yapması gerekenlerin neden önemli olduğunun yazıldığını katılımcıların \%62,5'i belirtmiştir. Yalnızca \%31,3'ü ise sayfaların çok yoğun olduğuna işaret etmiştir.

Sağlıklı yaşam broşürüne yönelik uzman önerilerinin hastalar tarafından da ifade edildiği görülmektedir. Tablo 6'da sağlıklı yaşam broşürü için verilen uzman önerileri içinden hastalarımız tarafından da en çok belirtilen 7 öneri yer almaktadır.

\section{Tablo 6. "Sağlıkı Yașam Broșürü” İçin Uzman Önerileri}

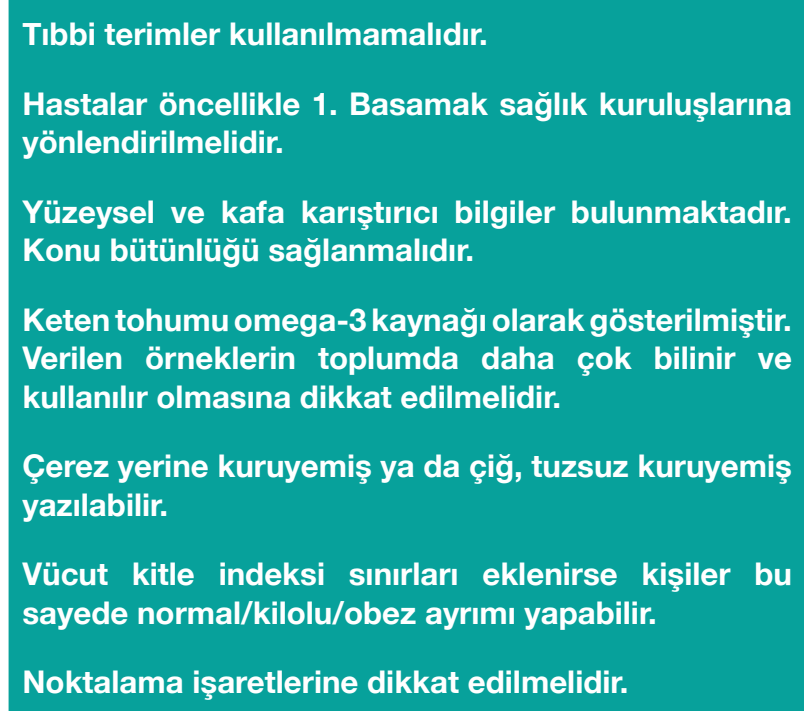

\section{TARTIŞMA}

Basılı sağlık eğitim materyalleri, farkındalığı ve bilgiyi artırmak, tutum ve inançları değiştirmek ve bireylerin sağlıklı yaşam tarzı davranışlarını benimsemelerine ve sürdürmelerine yardımcı olmak için yaygın olarak kullanımaktadır. Önceki araştırmalarda destekleyici yazılı materyaller sağlamanın tek başına sözlü tavsiye sunmaktan daha etkili olduğu vurgulandığı gibi, sağlık eğitimi materyallerinin tasarım özelliklerinin yanı sıra içerik özelliklerinin rolü ve önemi vurgulanmıştır (Bull, Holt, Kreuter, Clark, \& Scharff, 2001; Russell, Wilson, Taylor, \& Baker, 1979). 
Sağlık profesyonelleri için hastaları sözlü olarak eğitmek yaygın bir uygulama olsa da, sözlü olarak sunulan bilgileri desteklemek veya güçlendirmek için yazılı materyallerin kullanılması tavsiye edilir. Bu şekilde, hasta öğretiminin etkililiği, hastanın bilgisi ve tedavisi üzerinde olumlu bir etkiye sahip olabilir. Hastalar sözlü olarak verilen bilgileri sıklıkla unuturlar. Yazılı materyaller, bir kişinin hafızasını gerektiğinde yenilemek gibi bir avantaja sahiptir.

Hastaların soruları genellikle, sağlık profesyonelleri ile karşılaşma sırasında değil, onları görmeden önce veya gördükten sonra meydana gelir. Bir dereceye kadar, yazılı materyaller, bir sağlık uzmanıyla etkileşime girmediklerinde ortaya çıkan soruları yanıtlamada hastalara yardımcı olabilir. Yazılı materyallerin bir başka yararı, hastaların başa çıkma düzeyleri değiştikçe kendilerine en uygun bilgi düzeyini ve miktarını seçebilmeleridir. Sağlık profesyonelleri, hastaları eğitirken yaygın olarak yazılı sağlık eğitimi materyalleri kullanır, ancak çok azı hasta eğitim materyallerinin hazırlanması konusunda eğitim alır. Yazııı sağlık eğitimi materyalleri tasarlanırken, yazılı materyallerin etkinliğini en üst düzeye çıkarmak için dikkate alınması gereken bir dizi faktör vardır. Basitçe söylemek gerekirse, yazılı bilginin etkili olması için fark edilmesi, okunması, anlaşılması, inanıması ve hatırlanması gerekir (Hoffmann \& Worrall, 2004).

Sağlık okuryazarlığı düşük okuyucular için hazırlanan basit ve okunabilir materyaller tüm okuyucular tarafından tercih edilmiştir. Bu çalışmada da aynı şekilde uzmanlardan ve hastalardan alınmış olan önerilerin çoğu noktada kesiştiği görülmüştür.

Literatürde yer alan sağlık eğitim materyali hazırlama tavsiyelerine uygun olarak hazırlanan bu broşürler uzmanlar ve hastalar tarafından değerlendirilmiştir. Katılımcıların tamamı yazı tipi ve yazı büyüklüğünü uygun bulmuştur. Madde madde listelerin okumalarını kolaylaştırdığı yine tamamı tarafından ifade edilmiştir. Ana konu katıımcıların neredeyse tamamı tarafından anlaşılmışıı. Karışık tablo ve grafik olmadığını ifade etmiş̧lerdir.

Katılımcıların tamamı cümlelerin kendilerine hitap ettiğini belirtirken, $\% 80$ 'den fazlası ise anlamadığı terim olmadığını ifade etmiştir. Fakat katılımcıların yarısından fazlası yapması gerekenlerin neden önemli olduğunun yeterince anlatılmadığını düşünmüştür. Tansiyon ölçümü, randevu için nereye gidileceği, ilaçlarını nasıl alacakları konularında verilen bilgileri yetersiz bulmuşlardır. Bu konularda verdiğimiz bilgiler onlar için yüzeysel olarak kalmış bu konularda daha fazla bilgi verilmesinin önemli olduğu dikkatimizi çekmiştir. Ülkemizde sevk sistemi olmaması nedeniyle hastaların testler, ilaçlar veya randevular için belirli bir sürece yönlendirilmesi teknik olarak mümkün olmadığından broşürde değişiklik planlanmamıştır.
Broşürde hipertansiyon komplikasyonları anlatıldı̆ı halde başlık olarak belirtilmediğinden hastaların ve uzmanların dikkatini çekmediği görülmüştür.

Hastalar görsel eğitim materyallerinde sayfaların yoğun olduğunu da zaman zaman belirtmişlerdir. Bilgiyi verirken fazla veya yetersiz olmasından kaçınarak ancak intiyaç duyulan konulara nokta atışı yapmak şartı ile etkili ve uygun materyal hazırlanabileceği tekrar ortaya konulmuştur.

\section{SONUÇ VE ÖNERILER}

Sonuç olarak sağlık eğitim materyallerinin birey/hasta eğitimindeki önemine ve sağlık okuryazarlı̆ı düzeylerinin geliştirilmesine olan katkısına dikkat çekilmiştir. Etkili eğitim materyali hazırlarken dikkat edilecek hususlara yer verilmiştir. Sağlık profesyonellerini bu çalışmada yer alan tavsiyelere göre mevcut yazılı eğitim materyallerini gözden geçirmeye ve yeni yazılı sağlık eğitimi materyalleri tasarlarken bu tavsiyeleri uygulamaya teşvik etmeliyiz. Materyallerin etkinliğini en üst düzeye çıkarmak için kullanılan yazılı sağlık eğitim materyallerinin kalitesinin incelenmesi gerekmektedir. Yazılı materyallerin tasarımına ve pilot uygulamasına hastaları dahil etmenin faydaları görülmektedir. Hastaları bu sürece katmanın iyi tasarlanmış yazılı materyallere olan etkisini inceleyen kaliteli araştırmalara da intiyaç vardır.

\section{KAYNAKLAR / REFERENCES}

- Aşkın, U. D. L., Tanrıverdi, A. D. O., Türkmen, S., \& Aktürk, E. (2018). 2018 Avrupa Kardiyoloji Derneği/Avrupa Hipertansiyon Derneği Kılavuzu: Hipertansiyona Güncel Yaklaşımlar ve Tedavi Stratejileri.

- Avcl, E., \& Özkan, S. (2019). Dünya'da ve Türkiye'de sağlık okuryazarlığı düzeyi ve etkileyen faktörler. Sağlık Okuryazarlığı, 1, 16-21.

- Aydoğdu, S., Güler, K., Bayram, F., Altun, B., Derici, Ü., Abacı, A., ... Erdem, Y. (2019). Türk Hipertansiyon Uzlaşı Raporu 2019. Turk Kardiyol Dern Ars, 47(6), 535-546.

- Bull, F. C., Holt, C. L., Kreuter, M. W., Clark, E. M., \& Scharff, D. (2001). Understanding the effects of printed health education materials: which features lead to which outcomes? Journal of Health Communication, 6(3), 265-280.

- Çakır, B. (2017). Sağlıkı Yaşam: Gündelik Hayatta Karşılaştığımız Sağlık Risklerini Azaltabilir miyiz? Ankara Medical Journal, 17(3), 179-188.

- Çalışkan, D. (2019). Sağlık Okuryazarlığında Geliştirilmiş Materyalleri Kullanma ve Yeni Materyal Geliştirme. Sağlık Okuryazarlığı 1. Baskı. Ankara: Türkiye Klinikleri, 72-78.

- Hoffmann, T., \& Worrall, L. (2004). Designing effective written health education materials: considerations for health professionals. Disability and rehabilitation, 26(19), 1166-1173.

- Kindig, D. A., Panzer, A. M., \& Nielsen-Bohlman, L. (2004). Health literacy: a prescription to end confusion.

- Russell, M., Wilson, C., Taylor, C., \& Baker, C. (1979). Effect of general practitioners' advice against smoking. $\mathrm{Br}$ med $\mathrm{J}, 2(6184)$, 231-235.

- Tüzün, H., \& Özkan, S. (2019). Sağlık okuryazarlığı düze-yini artırmaya yönelik ulusal düzeyde yapılan-lar.

- Weiss, B. D. (2014). How to bridge the health literacy gap. Family practice management, 21(1), 14-18. 